\title{
Knowledge and attitudes of hospice and palliative care professionals towards diversity and religious literacy in Cyprus: a cross-sectional study
}

Panagiotis Pentaris \& Panayiota Christodoulou

\begin{abstract}
Background: This study is the first to document knowledge-base and knowledge attitudes about cultural competence and religious literacy in hospice and palliative care in Cyprus. Objective: The aim of this paper is to investigate and document the knowledge-base and attitudes towards advancing knowledge and expertise of hospice and palliative care professionals in Cyprus. Measurements: A cross-sectional selfadministered online survey, which reached 80 hospice and palliative care professionals, employed in the sector, was used. The response rate was $64 \%$, which increases the generalisability of the results. 41 surveys were completed fully and included in the study. Results: This study shows that self-awareness, reflexivity, respect towards the other and other people's culture and religion, are associated with current knowledgebase of the professionals, as well as attitudes toward future learning opportunities, lifelong learning and initiating learning between professionals and agencies. The results present three themes: knowledge development, knowledge empowerment and knowledge exchange. Conclusions: Professionals and organisations need to nurture and promote lifelong learning, supervision and enable individual practitioners to engage with activities that will enhance their self-awareness, reflexivity and attitude towards the unique identities of others.
\end{abstract}

Keywords: hospice; palliative care; Cyprus; religious literacy; cultural competence; knowledge; skills 


\section{Introduction}

Hospice and palliative care in Cyprus are predominantly available to cancer patients and by NGOs; specifically, the Cyprus Anti-Cancer Society (CACS), established in 1971, the Cyprus Association of Cancer Patients and Friends (PASYKAF), established in 1986, and the Bank of Cyprus Oncology Centre (BOCOC), established in 1998.1 A new General Public Health System was introduced in June 2019 which will include palliative care from June 1st, 2020 (https://www.gesy.org.cy). In other words, hospice and palliative care in Cyprus are yet to develop beyond cancer patients and adults, but also to be embedded in the healthcare system. Thus, the number of professionals that work in this field is small in comparison to people's needs altogether. Research in this area and context is also scarce and, when available, in the medical field.2-4 To the authors' knowledge, research concerning the perceptions and knowledge of health and social care professionals in this context is non-existent, unlike other geographies.5-6 Therefore, this study is the first of its kind since it explores the self-assessed awareness and knowledge on cultural competence and religious literacy of 41 health and social hospice and palliative care professionals. For the purposes of this study, the term 'cultural competence' refers to the "enhancement of skills and abilities to better engage with different cultures" and the term 'religious literacy' "suggests the need for developing an appropriate language and understanding of the multitude of faiths in society in order to nurture positive professional practice".7

\section{Methods}

This is a quantitative, cross-sectional study design that examines hospice and palliative care professionals' knowledge-base and attitudes towards the acquisition of new knowledge to improve cultural competence and religious literacy. It does so without influencing participants' subjectivity, 8 hence descriptive in nature.

\section{Study setting}

The study took place in Cyprus, a small-sized country with a little over 800,000 people, inclusive of migrants (app. 100.000). In this context, there is only one hospice. This hospice had 15 beds at the time of this study, but by the end of 2019 it will have 25. Further, given the little advancement of hospice and 
palliative care in Cyprus, very few professionals are employed in the field (this excludes expected end of life care provided in hospital settings).

\section{Sample and sampling method}

The population for this study was health and social care professionals who practice in hospice and palliative care in Cyprus. A combination of purposive sampling and the snowballing technique 9 was used to recruit participants. A call for participants went out from the Cyprus Anti-Cancer Society, the PASYKAF, Cyprus Muscular Dystrophy Association, the Cyprus Institute of Neurology and Genetics, Nursing Homes (Alzheimer's wing), Cyprus Social Work Association, Cyprus Psychologists Associations, and the newly formed Network of Hospice and Palliative Care Professionals in Cyprus. Professionals interested in partaking were provided with participant information and the opportunity to ask further questions of the researchers. Interested participants followed a link to the online survey on Qualtrics. If participants selected to continue to the survey, they also provided their consent for participation.

The main inclusion criteria for the study were that participants needed to be qualified in a health or social care profession (e.g. social work, medicine, nursing, paramedics, psychology) and practising in hospice and palliative care, whether this is in a specialist setting for palliative care, or other such as nursing homes.

\section{Measurement tool}

Drawing from the aspects of individual cultural competence considered in the Greater Vancouver Island Multicultural Society Cultural Competence Self-Assessment Checklist, 10 a self-assessment tool was created in the Greek language, which examines an individual professional's knowledge-base in palliative care and attitudes towards knowledge and development.

The questionnaire consists of 33 items, which are divided into three categories (i.e. knowledge, awareness and skills) that allow the exploration of the correlations between them to illuminate findings of each separately. The devised tool is a 5-point Likert scale type, and the answers range from never (1) to always (5). The face validity of the tool was measured by having it reviewed by an academic and a practitioner in the field, who confirmed the relevance of the statements. Next, the questionnaire was piloted with 10 professionals, to ensure the validity of the tool. Last, a Cronbach's alpha coefficient $(a=0.898)$ was run to test the tool's validity, which indicated high consistency. 


\section{Data analysis}

The data were entered and analysed using the SPSS version 25. Both univariate and bivariate descriptive analyses were carried out, and the varied relationships between the different items in the questionnaire were examined with the use of correlations (Pearson's) and regressions.

\section{Ethical considerations}

The study was approved by the Ethics Committee of the Frederick University in Cyprus (EEBK EP 2019.01.28). Each participant provided their consent to partake and had the chance to ask any further questions about the project. All participants had the right to withdraw at any time, without giving reason, or the right to refrain from answering any one question. Confidentiality and privacy of the information were stressed, and anonymity of the participants has been maintained at all times.

\section{Results}

\section{Descriptive statistics}

In light of the lack of formal recognition of hospice and palliative care in Cyprus, it is difficult to estimate the exact number of professionals in this area, however, more than $60 \%$ of the professionals who received the invitation partook in this study $(\mathrm{n}=53) .10$ responses consisted of missing values and 2 only provided their demographics. Hence, the total number of participants in this study was $n=41$. Table 1 presents the sample characteristics.

$84.8 \%$ of the participants claimed that they often or always feel that their knowledge about other cultures, ethnicities and religions is lacking and they seek further opportunities to develop. $94 \%$ of the participants highlight their understanding that culture, ethnicity and religion or non-religion are all unique and significant identities of the service users. Following this, 93\% state that continuing professional development and lifelong learning are important to maintain a most appropriate and effective way of working with people from other cultures, ethnicities and/or beliefs, while $96 \%$ of the participants continuously identify gaps in their knowledge and skills, in order to pursue a development plan. 
Table 1. Participants' characteristics

\begin{tabular}{|c|c|c|c|}
\hline Variable & & $\%(\mathrm{~N}=41)$ & Mean (SD) \\
\hline \multirow[t]{2}{*}{ Gender } & Male & $31.7 \%$ & - \\
\hline & Female & $68.3 \%$ & \\
\hline \multirow[t]{4}{*}{ Age } & $25-34$ & $61 \%$ & $30(0.865)$ \\
\hline & $35-44$ & $24.4 \%$ & \\
\hline & $45-54$ & $9.8 \%$ & \\
\hline & $55-64$ & $4.9 \%$ & \\
\hline \multirow[t]{2}{*}{ Nationality } & Cypriot & $90.2 \%$ & $-(0.3)$ \\
\hline & Greek & $9.8 \%$ & \\
\hline \multirow[t]{5}{*}{ Religion/Nonreligion } & Orthodox & $85.4 \%$ & - \\
\hline & Catholic & $2.4 \%$ & \\
\hline & Buddhist & $2.4 \%$ & \\
\hline & Atheist & $7.3 \%$ & \\
\hline & Spiritual & $2.4 \%$ & \\
\hline \multirow[t]{4}{*}{ Family structure } & Single & $32.5 \%$ & $(1.24)$ \\
\hline & $\begin{array}{l}\text { Married/in } \\
\text { partnership }\end{array}$ & $50 \%$ & \\
\hline & Divorced/separated & $5 \%$ & \\
\hline & Co-habiting & $12.5 \%$ & \\
\hline \multirow[t]{5}{*}{ Education } & College (IEK) & $2.4 \%$ & - \\
\hline & Undergraduate & $31.7 \%$ & \\
\hline & Postgraduate & $58.5 \%$ & \\
\hline & $\mathrm{PhD} /$ Doctorate & $4.9 \%$ & \\
\hline & Post-doctorate & $2.4 \%$ & \\
\hline \multirow[t]{8}{*}{ Discipline } & Nursing & $4.9 \%$ & - \\
\hline & Physician & $4.9 \%$ & \\
\hline & Social worker & $56.1 \%$ & \\
\hline & Psychologist & $17.1 \%$ & \\
\hline & Occupational & & \\
\hline & therapist & $7.3 \%$ & \\
\hline & Priest & $2.4 \%$ & \\
\hline & Other & $7.3 \%$ & \\
\hline \multirow[t]{4}{*}{ Sector } & Public & $22 \%$ & - \\
\hline & Private & $36.6 \%$ & \\
\hline & Voluntary & $34.1 \%$ & \\
\hline & Other & $7.3 \%$ & \\
\hline \multirow[t]{4}{*}{ Income } & $<€ 15.000$ & $31.7 \%$ & $€ 16.000-€ 25.000(0.961)$ \\
\hline & $€ 16.000-€ 25.000$ & $46.3 \%$ & \\
\hline & $€ 26.000-€ 35.000$ & $9.8 \%$ & \\
\hline & $>€ 36.000$ & $12.2 \%$ & \\
\hline \multirow[t]{6}{*}{ Overall experience } & $0-2$ years & $10.8 \%$ & $11-20$ years $(1.2)$ \\
\hline & $3-5$ years & $16.2 \%$ & \\
\hline & $6-10$ years & $24.3 \%$ & \\
\hline & $11-20$ years & $37.8 \%$ & \\
\hline & 21-30 years & $8.1 \%$ & \\
\hline & $31-40$ years & $2.7 \%$ & \\
\hline \multirow[t]{4}{*}{ Experience in palliative and hospice care } & $0-2$ years & $38.9 \%$ & 3 years $(1.1)$ \\
\hline & $3-5$ years & $27.8 \%$ & \\
\hline & $6-10$ years & $16.7 \%$ & \\
\hline & $11-20$ years & $16.7 \%$ & \\
\hline
\end{tabular}




\section{Inferential statistics}

Table 2 shows all correlations between the separate items in the questionnaire, while table 3 depicts the descriptions of the items appearing in table 2 and shows the mean and standard deviation $(S D)$ of each. For the purposes of this paper, only the correlations that focus on awareness and knowledge are examined; these are highlighted in table 2 and singled out below.

A Pearson's $r$ data analysis revealed a positive correlation between self-awareness of culture and belief and the avoidance to make biased professional judgments $(r=.54 ; \mathrm{p}<0.01)$. Equally, professionals with higher levels of self-awareness present a moderate positive correlation with the belief that new knowledge derives from gaining a better understanding of own culture and religion and sharing this understanding with others $(r=.36 ; \mathrm{p}<0.05)$. Awareness of own biases and stereotypes correlates positively with the tendency to engage with people from different backgrounds to increase knowledge $(r=.44 ; p<0.05)$, with actively seeking opportunities that will improve culturally and religiously sensitive practice $(r=.45 ; \mathrm{p}<0.05)$, with the tendency to promote and enable knowledge exchange between professionals, organisations and services $(\mathrm{r}=.50 ; \mathrm{p}<0.01)$, with the skill to be more attentive to others' beliefs before raising questions $(\mathrm{r}=.37 ; \mathrm{p}<0.05)$, and with the enablement of the learning of others $(r=.48 ; \mathrm{p}<0.05)$.

Further Pearson's $r$ data analysis showed a moderately positive relationship between self-understanding and the acknowledgement of limitations in one's knowledge about culturally competent and religiously literature hospice and palliative care $(\mathrm{r}=.38 ; \mathrm{p}<0.05)$. Reflection and commitment to lifelong learning are also associated $(\mathrm{r}=.40 ; \mathrm{p}<0.05)$. Other correlations include understanding of others' cultures and religions, and the promotion of knowledge exchange $(r=.50 ; \mathrm{p}<0.01)$; respecting others' cultures and religions and active engagement with learning opportunities $(\mathrm{r}=.41 ; \mathrm{p}<0.05)$, adaptability of communication skills required in cultural competence and religious literacy $(\mathrm{r}=.58 ; \mathrm{p}<0.01)$, the enablement of learning of others' $(\mathrm{r}=.48$; $\mathrm{p}<0.01)$, and knowledge exchange $(\mathrm{r}=.53 ; \mathrm{p}<0.01)$.

Additional analyses showed that continuous identification of potential gaps in knowledge and skills is positively linked with the ability to intervene with witnessing discrimination $(r=.51 ; \mathrm{p}<0.01)$, as well as the promotion of knowledge exchange $(\mathrm{r}=.41 ; \mathrm{p}<0.05)$. Next, professionals who identify that same identities may carry a different meaning for each person, also acknowledge inter-cultural differences $(\mathrm{r}=.39 ; \mathrm{p}<0.05)$. 
Last, awareness of how a host nation impacts on patients is positively correlated with the promotion of knowledge exchange $(\mathrm{r}=.39 ; \mathrm{p}<0.05)$, while the latter is associated with the ability to intervene when witnessing discrimination $(\mathrm{r}=.44 ; \mathrm{p}<0.05)$, and the ability to adapt skills to respond with cultural and religious sensitivity $(\mathrm{r}=.42 ; \mathrm{p}<0.05)$. 
Table 2. Awareness, knowledge and skills correlations

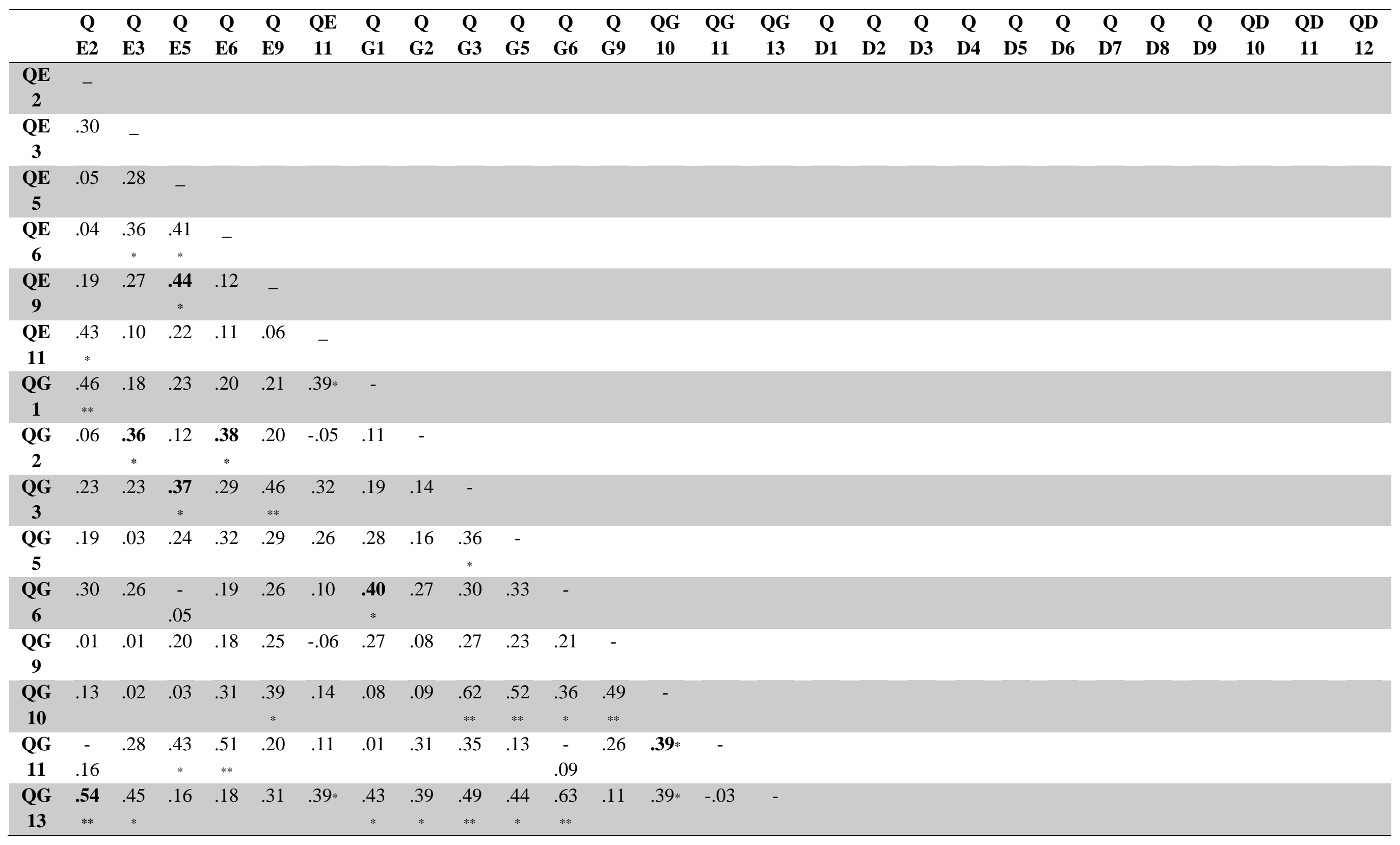




\begin{tabular}{|c|c|c|c|c|c|c|c|c|c|c|c|c|c|c|c|c|c|c|c|c|c|c|c|c|c|c|c|}
\hline $\begin{array}{c}\text { QD } \\
1\end{array}$ & .35 & $\begin{array}{c}- \\
.06\end{array}$ & .35 & .22 & $\begin{array}{l}.58 \\
* *\end{array}$ & $.40 *$ & .34 & $\begin{array}{l}- \\
.11\end{array}$ & $\begin{array}{l}.76 \\
* * *\end{array}$ & $\begin{array}{c}.44 \\
*\end{array}$ & .14 & .34 & $\begin{array}{c}.52 * \\
*\end{array}$ & .06 & .35 & - & & & & & & & & & & & \\
\hline $\begin{array}{c}\text { QD } \\
2\end{array}$ & $\begin{array}{c}- \\
.27\end{array}$ & $\begin{array}{c}- \\
.23\end{array}$ & .31 & .32 & .29 & -.12 & .05 & $\begin{array}{c}- \\
.02\end{array}$ & $\begin{array}{l}.40 \\
*\end{array}$ & .24 & .11 & $\begin{array}{c}.51 \\
* *\end{array}$ & .36 & .20 & .05 & $\begin{array}{c}.39 \\
*\end{array}$ & - & & & & & & & & & & \\
\hline $\begin{array}{c}\text { QD } \\
\mathbf{3}\end{array}$ & $\begin{array}{l}- \\
25\end{array}$ & .04 & $\begin{array}{l}.54 \\
* *\end{array}$ & $\begin{array}{c}.38 \\
*\end{array}$ & $\begin{array}{c}.44 \\
*\end{array}$ & .11 & .05 & .07 & $\begin{array}{l}.52 \\
* *\end{array}$ & .09 & $\begin{array}{l}- \\
15\end{array}$ & .31 & .22 & .35 & -.05 & $\begin{array}{c}.40 \\
*\end{array}$ & $\begin{array}{l}.63 \\
* *\end{array}$ & - & & & & & & & & & \\
\hline $\begin{array}{c}\text { QD } \\
4\end{array}$ & .09 & $\begin{array}{c}- \\
.15\end{array}$ & $\begin{array}{c}.45 \\
*\end{array}$ & .10 & .28 & .20 & .11 & $\begin{array}{c}- \\
.13\end{array}$ & .14 & .21 & $\begin{array}{c}- \\
.34\end{array}$ & .08 & -.12 & .02 & -.06 & $\begin{array}{c}.41 \\
*\end{array}$ & .37 & .20 & - & & & & & & & & \\
\hline $\begin{array}{c}\text { QD } \\
5\end{array}$ & .09 & .13 & $\begin{array}{c}.48 \\
*\end{array}$ & .05 & $\begin{array}{c}.46 \\
*\end{array}$ & .34 & .31 & $\begin{array}{c}- \\
.06\end{array}$ & .36 & .12 & $\begin{array}{c}- \\
.20\end{array}$ & .20 & -.11 & .06 & .06 & $\underset{* *}{.48}$ & .36 & $\begin{array}{c}.51 \\
* *\end{array}$ & $\begin{array}{c}.66 \\
* * *\end{array}$ & - & & & & & & & \\
\hline $\begin{array}{c}\text { QD } \\
6\end{array}$ & $\begin{array}{l}- \\
.21\end{array}$ & $\begin{array}{c}- \\
.37 \\
*\end{array}$ & .15 & .00 & .23 & .04 & $\begin{array}{c}- \\
.04\end{array}$ & $\begin{array}{c}- \\
.13\end{array}$ & $\begin{array}{l}.52 \\
* *\end{array}$ & .35 & $\begin{array}{c}- \\
.10\end{array}$ & $\begin{array}{l}.53 \\
* *\end{array}$ & $\begin{array}{c}.50 * \\
*\end{array}$ & .24 & -.05 & $\begin{array}{l}.52 \\
* *\end{array}$ & $\begin{array}{l}.52 \\
* *\end{array}$ & .36 & $\begin{array}{c}.39 \\
*\end{array}$ & .30 & - & & & & & & \\
\hline $\begin{array}{c}\text { QD } \\
7\end{array}$ & .17 & $\begin{array}{c}- \\
.01\end{array}$ & .37 & .09 & .36 & .07 & $\begin{array}{c}- \\
.07\end{array}$ & $\begin{array}{c}- \\
.08\end{array}$ & .29 & .25 & $\begin{array}{c}- \\
.14\end{array}$ & .33 & .37 & .08 & -.07 & $\begin{array}{c}.39 \\
*\end{array}$ & .27 & .17 & $\begin{array}{c}.43 \\
*\end{array}$ & .25 & $\begin{array}{l}.54 \\
* *\end{array}$ & - & & & & & \\
\hline $\begin{array}{c}\text { QD } \\
8\end{array}$ & .02 & $\begin{array}{c}- \\
.22\end{array}$ & .36 & $\begin{array}{c}- \\
.22\end{array}$ & $\begin{array}{l}.56 \\
* *\end{array}$ & .08 & $\begin{array}{c}- \\
.06\end{array}$ & $\begin{array}{c}- \\
.34\end{array}$ & .33 & .30 & $\begin{array}{c}- \\
.21\end{array}$ & $\begin{array}{c}.41 \\
*\end{array}$ & .29 & .25 & -.16 & .47 & .25 & .26 & $\begin{array}{l}.51 \\
* *\end{array}$ & .36 & .50 & $\begin{array}{c}.41 \\
*\end{array}$ & - & & & & \\
\hline $\begin{array}{c}\text { QD } \\
9\end{array}$ & .09 & $\begin{array}{c}- \\
.17\end{array}$ & $\begin{array}{c}\mathbf{5 0} \\
* * *\end{array}$ & .01 & $\begin{array}{l}.52 \\
* *\end{array}$ & $.39 *$ & .19 & $\begin{array}{c}- \\
.35\end{array}$ & $\begin{array}{l}.50 \\
* *\end{array}$ & $\begin{array}{l}.50 \\
* * *\end{array}$ & $\begin{array}{c}- \\
.03\end{array}$ & $\begin{array}{c}.41 \\
*\end{array}$ & .33 & .16 & -.06 & $\begin{array}{l}.53 \\
* *\end{array}$ & $\begin{array}{c}.44 \\
*\end{array}$ & $\begin{array}{c}.42 \\
*\end{array}$ & $\begin{array}{l}.55 \\
* *\end{array}$ & $\begin{array}{l}.57 \\
* * *\end{array}$ & $\begin{array}{c}.62 \\
* *\end{array}$ & $\begin{array}{c}.58 \\
* * *\end{array}$ & $\begin{array}{c}.71 \\
* * *\end{array}$ & - & & & \\
\hline $\begin{array}{c}\text { QD } \\
10\end{array}$ & .06 & $\begin{array}{c}- \\
.18\end{array}$ & $\begin{array}{c}.46 \\
*\end{array}$ & $\begin{array}{c}- \\
.07\end{array}$ & $\begin{array}{l}.50 \\
* *\end{array}$ & .29 & .04 & $\begin{array}{c}- \\
.42 \\
*\end{array}$ & $\begin{array}{c}.43 \\
*\end{array}$ & $\begin{array}{c}.39 \\
*\end{array}$ & $\begin{array}{c}- \\
.22\end{array}$ & .25 & .23 & .07 & -.04 & $\begin{array}{c}.58 \\
* * *\end{array}$ & .36 & .32 & $\begin{array}{l}.70 \\
* *\end{array}$ & $\begin{array}{l}.55 \\
* *\end{array}$ & $\begin{array}{l}.67 \\
* *\end{array}$ & $\begin{array}{l}.64 \\
* *\end{array}$ & $\begin{array}{c}.78 \\
* *\end{array}$ & $\begin{array}{c}.86 \\
* * *\end{array}$ & - & & \\
\hline $\begin{array}{l}\text { QD } \\
11\end{array}$ & .36 & $\begin{array}{l}- \\
.28\end{array}$ & $\begin{array}{c}.43 \\
*\end{array}$ & $\begin{array}{c}- \\
.03\end{array}$ & .25 & $.42 *$ & .16 & $\begin{array}{c}- \\
.45 \\
*\end{array}$ & .29 & .12 & $\begin{array}{c}- \\
.28\end{array}$ & .21 & -.05 & -.06 & -.14 & $\begin{array}{l}.57 \\
* *\end{array}$ & .21 & .17 & $\begin{array}{l}.74 \\
* *\end{array}$ & $\begin{array}{l}.57 \\
* *\end{array}$ & $\begin{array}{c}.41 \\
*\end{array}$ & $\begin{array}{c}.45 \\
*\end{array}$ & $\begin{array}{l}.60 \\
* *\end{array}$ & $\begin{array}{c}.68 \\
* * *\end{array}$ & $\begin{array}{c}.72 * \\
*\end{array}$ & - & \\
\hline $\begin{array}{l}\text { QD } \\
12\end{array}$ & $\begin{array}{c}- \\
.01\end{array}$ & $\begin{array}{l}- \\
.18\end{array}$ & $\begin{array}{l}.51 \\
* *\end{array}$ & .02 & .24 & .24 & $\begin{array}{c}- \\
.06\end{array}$ & $\begin{array}{c}- \\
.32\end{array}$ & .27 & .21 & $\begin{array}{c}- \\
.25\end{array}$ & .07 & .06 & .17 & -.10 & $\begin{array}{c}.45 \\
*\end{array}$ & .29 & .09 & $\begin{array}{c}.72 \\
* *\end{array}$ & .34 & $\begin{array}{l}.58 \\
* * *\end{array}$ & $\begin{array}{c}.47 \\
*\end{array}$ & $\begin{array}{l}.55 \\
* *\end{array}$ & $\begin{array}{c}.56 \\
* *\end{array}$ & $\begin{array}{c}.76 * \\
*\end{array}$ & $\begin{array}{c}.69 * \\
*\end{array}$ & - \\
\hline
\end{tabular}




\begin{tabular}{|c|c|c|c|}
\hline Code/Item & Description & Mean & SD \\
\hline QE2 & Self-awareness about own culture, nationality and/or religion and belief & 3.62 & .64 \\
\hline QE3 & $\begin{array}{l}\text { In order to enhance own knowledge about others' culture and religion, becoming fully aware of own identities and sharing that } \\
\text { knowledge is essential }\end{array}$ & 3.62 & .57 \\
\hline QE5 & $\begin{array}{l}\text { I am fully aware of all implicit and explicit assumptions I make about people with a different cultural or religious identity than } \\
\text { mine }\end{array}$ & 3.12 & .71 \\
\hline QE6 & My own cultural and religious beliefs influence professional judgment and decisions, as well as a structured notion of 'normality' & 3.31 & .62 \\
\hline QE9 & I seize all opportunities to engage with people from different backgrounds, in order to increase my knowledge and build rapport & 2.81 & .69 \\
\hline QE11 & $\begin{array}{l}\text { I appreciate that challenges in the social life of the host nation may further impact on the lives of migrants or people with different } \\
\text { than the normative identities }\end{array}$ & 3.35 & .63 \\
\hline QG1 & I learn from my mistakes & 3.42 & .64 \\
\hline QG2 & I acknowledge the limitations of my knowledge about other cultures and religions, and I will create opportunities to learn more & 3.27 & .67 \\
\hline QG3 & I carefully listen to the other's perspective before asking further questions & 3.42 & .70 \\
\hline QG5 & Cultural and religious beliefs are ever-changing and differ from person to person & 3.62 & .57 \\
\hline QG6 & Cultural competence and religious literacy necessitate commitment to lifelong learning & 3.62 & .64 \\
\hline QG9 & I will continue to hone my skills in identifying gaps in my knowledge and skills, in order to further develop professionally & 3.73 & .53 \\
\hline QG10 & Each person has more than one identity, which inter-link and have a different meaning for each person & 3.65 & .49 \\
\hline QG11 & I can identify inter-cultural and inter-religious differences & 3.23 & .76 \\
\hline QG13 & My culture and/or religion should not be informants of my perception of what is appropriate or inappropriate & 3.58 & .64 \\
\hline QD1 & I interact with others with respect & 3.54 & .58 \\
\hline QD2 & I can intervene with effect when someone is treated with discrimination & 3.27 & .60 \\
\hline QD3 & I can adapt my communication style and methods to better work with people from different cultures and/or religions, if need be & 3.65 & .49 \\
\hline QD4 & I actively seek opportunities to engage with others who will support my learning and development in this area & 3.12 & .65 \\
\hline QD5 & I encourage and promote knowledge exchange to other professionals & 3.38 & .80 \\
\hline QD6 & I can practice in a respectful way towards others' cultures and religions & 3.69 & .47 \\
\hline QD7 & I am aware of the organisational protocols and relevant legislation to enable me to practice more effectively & 3.04 & .92 \\
\hline QD8 & $\begin{array}{l}\text { My colleagues who are of different cultural and/or religious background than mine, consider me a culturally and religiously } \\
\text { sensitive person, who will support others regardless of their identities }\end{array}$ & 3.38 & 1.02 \\
\hline
\end{tabular}




\begin{tabular}{|c|c|c|c|}
\hline QD9 & $\begin{array}{l}\text { I actively promote and encourage knowledge exchange about cultural competency and religious literacy between professionals, } \\
\text { colleagues, services and organisations or institutions }\end{array}$ & 3.23 & .95 \\
\hline QD10 & $\begin{array}{l}\text { I have knowledge of a variety of communication methods and other skills that enable me to practice effectively with people from } \\
\text { varied backgrounds }\end{array}$ & 3.27 & .78 \\
\hline QD11 & I am fully able to identify biased attitudes or implicit assumptions of mine and will not act based on those & 3.46 & .81 \\
\hline QD12 & $\begin{array}{l}\text { I appreciate the differences within a single culture or religion, and I will avoid generalising my knowledge but apply it separately } \\
\text { for each person }\end{array}$ & 3.35 & .69 \\
\hline
\end{tabular}




\section{Discussion}

The results of this study show a group of highly confident professionals in hospice and palliative care, as well as committed to lifelong learning and CPD. Three attitudes towards the acquisition of new and specialist knowledge are recorded: knowledge development, knowledge empowerment and knowledge exchange (Figure 1), all of which are indicators of higher levels of culturally competent and religiously literate hospice and palliative care.

Figure 1. Knowledge attitudes towards learning and development in cultural competence and religious literacy

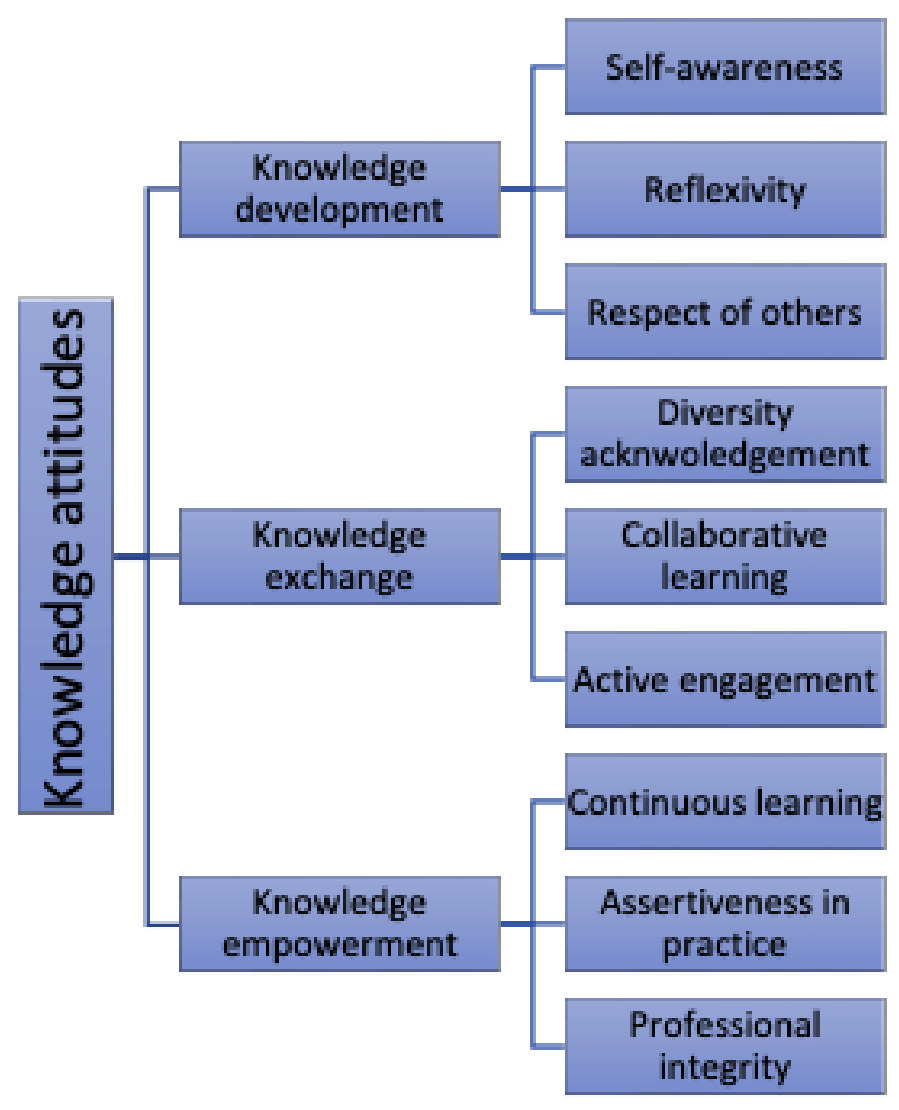

\section{Knowledge development}

Self-awareness, reflexivity and respect appear to be the key drives to actively seek knowledge development; whether this derives from learning from others, or from reflection. The findings in this study highlight that higher levels of reflection in practice and self-awareness indicate the enfranchisement of 'the other' and the willingness to learn from them and develop professionally. This study adds to the argument of Ho Chan and Tin,11 who explored death competencies that were noted in palliative professionals and concluded that 
knowledge competence is one of the key areas which professionals consider to be the most important in order to carry out their tasks. The present study adds to this and identifies dependency between the ability to develop knowledge competence and self-awareness, reflexivity and respect.

\section{Knowledge exchange}

Self-awareness is also the most influential factor of a professional's perspectives and attitude towards knowledge exchange between professionals, services and organisations. Ho Chan and Tin11 indirectly refer to self-awareness as well when discussing self-competence, and studies like Smith et al.12 verify that enhanced self-awareness in professionals will increase their knowledge and skills, or at least the potential for further development.

The present study highlights that the more professionals acknowledge diversity and the challenges of multiculturalism, the more often they promote, but also initiate collaborative learning via peer supervision or 1:1 exchange, formally or informally, within and across organisations. Knowledge exchange is promoted when professionals understand and respect others' culture and religion and are actively engaged in this area by seizing learning opportunities, adapting to pertinent communication skills and enabling learning for others. The conceptions of knowledge exchange found in this study link with König's argumentı3; culture is not a simple trait but in constant recreation, and professionals ought to engage in a multi-professional, interprofessional and cross-agency dialogue to continuously be updated about the culture of the other.

\section{Knowledge empowerment}

The data also indicated that professionals who employ active methods of continuous learning, also demonstrate higher levels of assertiveness in their practice with people from different backgrounds than their own. This is paramount in the advancement of one's professional integrity altogether.

Pentaris' work14 highlights that increased religious literacy leads to higher professional assertiveness. In this case, religious literacy is also dependent on knowledge advancement and understanding of how to best use that knowledge, both of which link with knowledge empowerment and the principle of initiative taking. This study highlights the importance of continuing professional development as it improves professional integrity.

\section{General discussion}


Specialist training in this area was never provided to the participants. Yet, this study shows that most of them are self-aware of their levels of knowledge and understanding of others' cultures and religions. In fact, the study denotes that professionals who are more self-aware of culture and beliefs of others are more selfaware of their own cultural views and beliefs thus they do not haste to judge or make professional decisions based on their own beliefs. Most of the participants understand that to gain new knowledge they need to understand their own culture and religion and share this understanding with others. However, the findings cannot indicate whether their attitudes and knowledge derive from experience or expertise. Drawing on the Hospice Palliative Care competencies by Bosma et al., 15 expertise remains important and highly pertinent when exploring attitudes towards professional growth and development, as well as the advancement of reflective practice, which, in turn, leads to higher levels of cultural competences and religious literacy.14-16 The findings of this study complement the work of Psaltis et al.,17 about the social acceptance of Cypriots towards people of different backgrounds; yet, suggest lack of individual acceptance.

It is worth noting that the study indicates the lack of organisational policies/protocols concerning effective practices towards the professionals' approaches to others' cultures and religions. However, it reveals that organisations are culturally sensitive, hence supportive. Pentaris and Thomsen argue that 'If the organizational philosophy encourages cultural reflexivity and flexibility, it supports the professional development of cultural sensitivity'.7 Yet, policies and guidance are paramount in shaping practice that is both culturally competent and religiously literate.14,18

\section{Study limitations}

Hospice and palliative care in Cyprus remain an underdeveloped area of practice. It is not possible to target all professionals in this field, when conceptions of how practice fits in the realms of hospice and palliative care vary widely. Further, the dearth of empirical data in this area in Cyprus is both a strength and a weakness; strength as it increases its innovation, originality and contribution, but a weakness as there is no firm body of literature in which this new knowledge can be situated. The sample was unavoidably homogenous, given the fairly recent advancements in hospice and palliative care in Cyprus. Further, the sample is not a clear representation of the public in Cyprus; while government statistics about the general public do not recommend positive attitudes towards other cultures and religions, mostly in the form of 
microaggressions, the participants of this study present a different image; respect and understanding of the other. This may be representative of hospice and palliative care staff, nonetheless. Last, the methodology used for this study causes limitations in the extent to which the information can be understood.

\section{Clinical implications}

This study recommends that methods like supervision and reflective exercises should be used more widely and specifically to increase self-awareness, respect towards others and reflexivity, which will thus enhance hospice and palliative professionals' cultural competence and religious literacy, both of which are paramount in practice, whether among clinical or allied professions. In addition, the study suggests that enablement to continuing professional development will lead to enhanced professional integrity and sensitive practice. This said, the findings will inform the development of a CPD course that will train professionals in cultural competence and religious literacy in hospice and palliative care.

\section{Conclusions}

Even though Cypriot society is not as hospitable towards other cultures and religions, 17 the participants of this study show respect and an understanding towards others' cultures and religions. This may be a quality found in hospice and palliative professionals, but further research will need to explore it. The need for further training on cultural competence and religious literacy is highlighted. Further research could be conducted to explore patients' perceptions on the professionals' cultural competence and religious literacy. In this way a comparative study could follow. Lastly, the lack of policies on diversity in hospice and palliative care should be further researched in Cyprus, to enable organisational growth in this area. End of life care policy is in the making, but further evidence like this study is paramount to strengthen recommendations.

\section{Disclosures and acknowledgements}

We thank the organisations and professionals who kindly supported the study and contributed to its overall aim. Warm thanks to the Cyprus Anti-Cancer Society and the Cyprus Association of Cancer Patients and Friends for their committed support to the advancement of research and knowledge in this area. 


\section{Compliance with ethical standards}

All procedures performed were approved by the National Bioethics Committee of Cyprus which is ethically responsible for all academic research in Cyprus (EEBK EP 2019.01.28).

\section{Conflict of interest statement}

The authors declare that they have no conflict of interest.

\section{References}

1. Charalambous H, Pitsillides B, Nestoros S: Palliative care in Cyprus: current status. In: Silberman M. (ed.): Palliative care to the cancer patient. New York, NY: Nova Publishers, 2014, pp. 1-20.

2. Silbermann M, Fink RM, Min SJ, et al: Evaluating palliative care needs in Middle Eastern countries. J Palliat Med 2015; 18(1):18-25.

3. Bingley A, Clark D: A comparative review of palliative care development in six countries represented by the Middle East Cancer Consortium (MECC). J Pain Symptom Manag 2009; 37(3):287-296.

4. Klepstad P, Kaasa S, Cherny N, et al.: Pain and pain treatments in European palliative care units. A cross sectional survey from the European Association for Palliative Care Research Network. Palliative Med 2005; 19(6), 477-484.

5. Von Gunten CF, Mullan PB, Nelesen R, et al.: Primary care residents improve knowledge, skills, attitudes, and practice after a clinical curriculum with a hospice. Am J Hosp Palliat Me 2017; 34(8):713-720.

6. Von Gunten CF, Twaddle M, Preodor M, et al.: Evidence of improved knowledge and skills after an elective rotation in a hospice and palliative care programme for internal medicine residents. Am $\mathbf{J}$ Hosp Palliat Me 2005; 22(3):195-203. 
7. Pentaris P, Thomsen LL: Cultural and religious diversity in hospice and palliative care: a qualitative cross-country comparative analysis of the challenges of health-care professionals. OMEGA-J Death Dying 2018; 2018:1-22. doi.org/10.1177/0030222818795282

8. Social research methods. Bryman A. Oxford university press, Oxford, 2016.

9. Designing qualitative research. Flick U. Sage, London, UK, 2018.

10. Greater Vancouver Island Multicultural Society. Greater Vancouver Island Multicultural Society Cultural Competence Self-Assessment Checklist. Available at www.cvims.org; n.d.

11. Ho Chan WC, Tin AF: Beyond knowledge and skills: Self-competence in working with death, dying, and bereavement. Death Stud 2012; 36(10):899-913.

12. Smith RC, Dorsey AM, Lyles JS, Frankel RM: Teaching self-awareness enhances learning about patient-centered interviewing. Acad Med 1999; 74(11):1242-1248.

13. König J. Moving experience: Dialogues between personal cultural positions. Culture \& Psychology 2009; 15(1):97-119.

14. Religious literacy in hospice care: challenges and controversies. Pentaris P. Routledge, London, UK, 2019.

15. Bosma H, Johnston M, Cadell S, et al.: Creating social work competencies for social work in hospice palliative care. Palliative Med 2010: 24(1):79-87.

16. Pentaris P: Religious competence in social work practice: the UK picture. Social Work \& Society $2012 ; 10(2): 1-4$.

17. Psaltis C, Kadianaki I, Nicolaou A, Panagiotou E: Perceptions of Cypriots about Refugee and Migrants. University of Cyprus Center for Field Studies \& UNHCR, the UN Refugee Agency, Cyprus. Retrieved on 10.9.2019 from: https://www.unhcr.org/cy/wpcontent/uploads/sites/41/2019/03/Perceptions_FULL-REPORT-FINAL_8March2019.pdf; 2019.

18. Borgstrom E, Walter T: Choice and compassion at the end of life: a critical analysis of recent English policy discourse. Soc Sci Med 2015; 136:99-105. 